\title{
Designing Geothermal Heating and Cooling System
}

\author{
Prateek Mahapatra \\ Department of Mechanical Engineering \\ Manav Rachna University \\ Faridabad, India
}

\author{
Shivam Singh \\ Department of Mechanical Engineering \\ Manav Rachna University \\ Faridabad, India
}

\begin{abstract}
The main objective of this study is to propose a simple design of geothermal heating and cooling system and test this design's feasibility. Findings: In this study, it was observed that this system was able to maintain a room temperature of $25^{\circ} \mathrm{C}$. Novelty/Applications: The novelty lies in the use of the concept of constant ground temperatures of the earth in an air conditioning system that uses water as a refrigerant with no use of heat pump which can provide both heating and cooling. This system can be modified or upgraded according to the needs of a person. This system can be a replacement for air coolers in industries where air conditioners cannot be used.
\end{abstract}

Keywords- Geothermal energy; Air conditioning system; Heat exchanger; HVAC systems.

\section{INTRODUCTION}

A ground-coupled heat exchanger is an underground heat exchanger that can capture heat from the ground and can also dissipate heat to the ground. They use the Earth's near-constant subterranean temperature to warm or cool air or other fluid for residential, agricultural, or industrial uses [1]. This paper deals in-depth with our demonstration of using Geothermal energy as a future alternative to traditional heating and air conditioning systems. Geothermal energy is the energy that is harnessed from the mother earth. A geothermal air conditioning system is considered to be the most efficient air conditioning system available to date on this planet [2]. A Ground Coupled Heat Exchanger is a cheaper and greener alternative of evaporative cooler and air conditioning system. It is a type of renewable energy system that usually exchanges heat with the ground or earth rather than the ambient air (Atmospheric air in the neutral state). As we all know that the temperature of the ambient air fluctuates throughout the year but in case of the ground the temperature of the ground at a certain depth stays relatively constant (nearly around $20^{\circ}-25^{\circ} \mathrm{C}$ ) throughout the year all around the globe. The ground-coupled heat exchanger exchanges heat with the heat sink i.e. (ground) at nearly constant temperature rather than exchanging heat with heat sink i.e. (ambient air). The major advantage of exchanging heat with the ground at constant temperature rather than with ambient air at fluctuating temperature is it usually consumes the same amount of electricity throughout the year. While in the case of ambient air the electricity consumption varies according to the working load. For example in summer the working load is more as more amount of energy is required to pump heat from room to cooled and already hotter heat sink whereas in winter the temperature of the heat sink is low so directly the amount of workload as well as energy consumption is low. So, comparatively ground or earth as a heat-sink is an economical way than a conventional system having ambient air as heat-sink when electricity consumption is considered. As ground and water temperatures, 4-6 feet below the earth's surface, stay relatively constant throughout the year. This allows the system to provide extremely efficient heating or cooling all year long in virtually any climate. Systems based on geothermal energy cool in much the same way that they heat, moving hot air through a geothermal heat pump or air-to-liquid transfer. In the case of cooling, geothermal systems move heat from above ground to the cooler environment 20 feet under the earth's surface. Water circulated through a geothermal loop carries heat below the earth's surface, where it is absorbed into the ground; the cooled water is then carried back up to regulate the higher ambient temperature. Due to the mass of the earth below, geothermal systems can cool even intense sources of heat. Geothermal cooling is used in green data centers and various industrial environments with almost no power use, no carbon production, and no water used but that which exists within the closed system.

\section{PRINCIPLE OF OPERATION}

The Geothermal heating and cooling system work on the phenomena of the earth having constant temperature throughout the year around the globe below a certain depth beneath the earth's surface. Usually, it is $20-25^{\circ} \mathrm{C}$ but may vary according to certain geological and geographical conditions [1]. The heat transfer rate between the geothermal heating and cooling system and earth depends upon the conductivity of soil, the thermal inertia of soil along with many other parameters like water holding capacity of the soil, and the depth [2]. There is some efficiency advantage of geothermal heating and cooling system over evaporative air cooler and air conditioning system is Geothermal heating systems can extract up to six times the heat energy they use in electrical energy.

The system consists of the following parts i.e. air filter (4), water reservoir (2), water pump (3), cooling coils (5), fan (6), AC cooler motor (6), and HDPE pipes (1). 


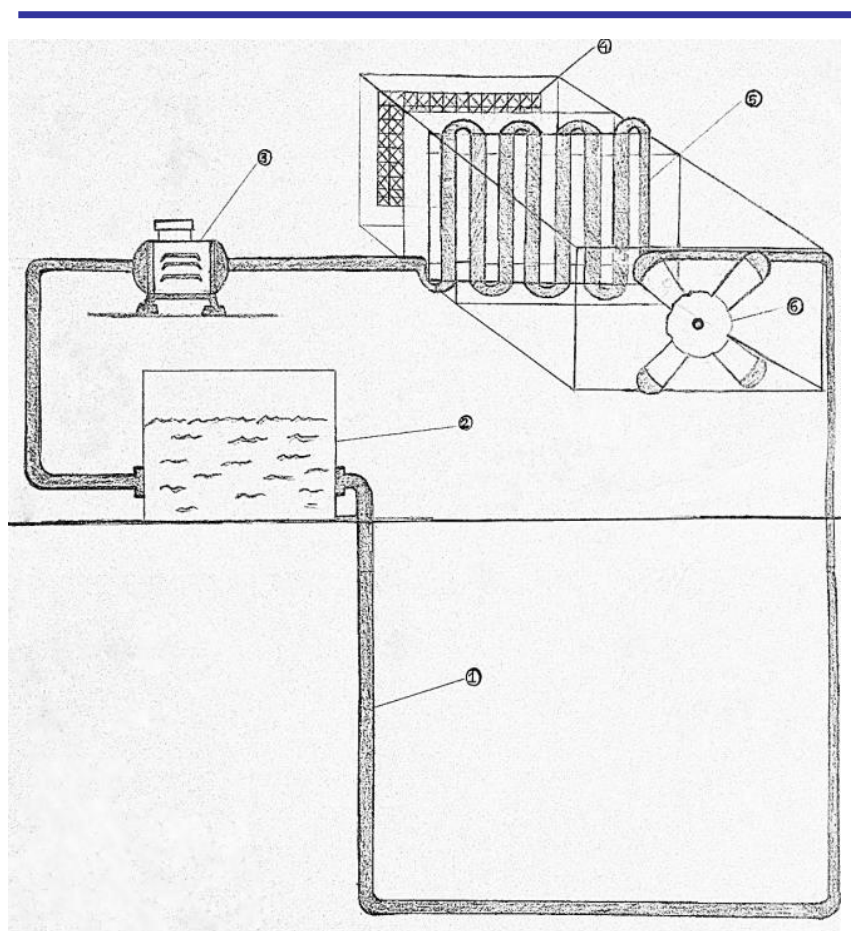

Figure 1: Diagram of Geothermal Heating and Cooling System

The system consists of the following parts i.e. air filter (4), water reservoir (2), water pump (3), cooling coils (5), fan (6), AC cooler motor (6), and HDPE pipes (1). First, the water stored inside the water reservoir (2) or tank is pumped out using a domestic water pump (3) and is transported to the cooling system where it will flow through the loops of copper tube or cooling coil (5) inside the cooling unit. Then hot air from the surrounding is extracted or sucked in by the cooling unit which consists of an external casing, air filters (4), copper tube loops or cooling coil (5), AC cooler motor (6), and fan (6). Now the hot air sucked in will give its heat to the copper tube by convection thus cold air will flow out of the cooling unit and then the hot copper tube will transfer its heat to the cold water flowing inside it by convection. Now the hot water will flow out of the cooling unit through HDPE pipes (1) into the ground. As we know that the temperatures 4-6 $\mathrm{ft}$ below earth surface remain constant throughout the year as the ground absorbs nearly half of the solar energy our planet receives and at even greater depths around 3-5 meters the temperatures are even lower. Deep below the earth's surface, we will be having a network of HDPE pipes (1) or ground loops which will transfer heat from hot water to the ground which will act as a heat sink due to which water will again become cold or regain its initial temperature. Then the cold water flows through the HDPE pipe (1) and gets collected in the water reservoir (2) and this cycle is continuously repeated thus cooling the room. Similarly in the winter season, the ground is hotter so it will work as an indoor heater.

\section{EXPERIMENTAL PROCEDURE}

The objective of this paper is to design a geothermal heating and cooling system and to test this system's feasibility. For testing this system we consider a standard bedroom of dimensions $12 \mathrm{ft} * 10 \mathrm{ft} * 10 \mathrm{ft}$ then the volume of the room will be $1200 \mathrm{ft}^{3}$ and to calculate the value of CFM (Cubic feet per minute) we are using the formula i.e. (Room Volume $) /(60$ Minutes $) \times$ number of times the air in the room should be changed in one hour. According to the air exchange index, the typical air change per hour for a room is considered to be 6 so for the selected room size of $1200 \mathrm{ft}^{3}$ the value of CFM will be 120 . Now for the required room, we need to calculate the value of cooling coil load and size of cooling coil and to calculate these values we considered the following data i.e. the airflow as $120 \mathrm{CFM}$, the water pump pumps water at $0.23 \mathrm{Kilogram} / \mathrm{second}$, outside air temperature as $45^{\circ} \mathrm{C}$ and required room air temperature as $25^{\circ} \mathrm{C}$. Then from these data, we calculate the specific volume and specific humidity of air at the inlet and outlet of the system using Figure 1: Psychrometric Chart. After finding these values we calculate the enthalpy of air at the inlet and outlet of the system. From these obtained values we calculated the dry air mass volume flow rate and condensate water mass flow rate. Then after calculating all these values we calculate the cooling load of this system. Then for the sizing of the cooling coil, we calculate the surface area required for convective heat transfer.

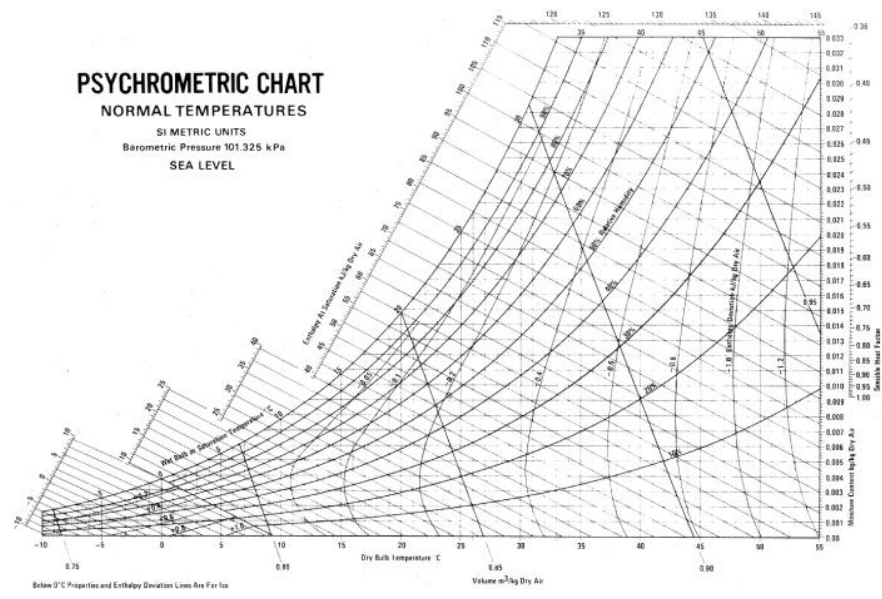

Figure 2: Psychrometric Chart

TABLE 1

\begin{tabular}{|c|c|c|}
\hline Property & Air In & Air Out \\
\hline $\begin{array}{c}\text { Air Volume Flow Rate } \\
\left(\mathrm{V}^{*}\right)\end{array}$ & $0.056 \mathrm{~m}^{3} / \mathrm{s}$ & - \\
\hline Air Temperature (T) & $45^{\circ} \mathrm{C}$ & $2{ }^{\circ} \mathrm{C}$ \\
\hline Relative Humidity $(\mathrm{RH})$ & $50 \%$ & $100 \%$ \\
\hline Specific Volume $\left(\mathrm{V}_{1}\right)$ & $0.9 \mathrm{~m}^{3} / \mathrm{s}($ Dry Air $)$ & \\
\hline Specific Humidity $(\mathrm{W})$ & $\mathrm{W}_{1}=0.031$ & $\mathrm{~W}_{2}=0.020$ \\
\hline & $\mathrm{h}_{1}=(1.006 \times 45)+$ & $\mathrm{h}_{2}=(1.006 \times 25)+$ \\
& $0.031 \times[(1.84 \times 45)$ & $0.020 \times[(1.84 \times 25)+$ \\
Enthalpy (h) & $+2501]=125.36$ & $2501]=76.09$ \\
& $\mathrm{KJ} / \mathrm{Kg}$ & $\mathrm{KJ} / \mathrm{Kg}$ \\
\hline
\end{tabular}

Dry air mass volume flow rate $\left(M_{a}{ }^{*}\right)=V^{*} / V_{l}$

$M a^{*}=0.056 / 0.9=0.062 \mathrm{Kg} / \mathrm{s}$

Condensate water mass flow rate $\left(M w^{*}\right)=M_{a}^{*} \times\left(W_{1}-W_{2}\right)$

$M w^{*}=0.062 \times(0.031-0.020)=0.0006 \mathrm{Kg} / \mathrm{s}$ 
TABLE 2

\begin{tabular}{|c|c|c|}
\hline S.No. & Parameters & Values \\
\hline 1. & Cooling Water Mass Flow Rate $\left(\mathrm{M}^{*}\right)$ & $0.23 \mathrm{Kg} / \mathrm{s}$ \\
\hline 2. & Water Inlet Temperature & $25^{\circ} \mathrm{C}$ \\
\hline 3. & Water Specific Heat Capacity $(\mathrm{Cp})$ & $4.2 \mathrm{KJ} / \mathrm{Kg} \mathrm{K}$ \\
\hline 4. & Water Out Condensate Water \\
\hline 5. & Temperature & $45^{\circ} \mathrm{C}$ \\
\hline
\end{tabular}

Cooling Load $\left(Q^{*}\right)=M a^{*} \times\left(h_{2}-h_{1}\right)+\left(M_{w}{ }^{*} \times h_{w}\right)$

$Q^{*}=[0.062 \times(76.09-125.36)]+(0.0006 \times 104.83)=$ $2.9 \mathrm{KW}=2.9 \mathrm{KJ} / \mathrm{s}$

Cooling coil outlet temperature $\left(T_{\text {out }}\right)=T_{\text {in }}+Q^{*} /\left(M^{*} \times C_{p}\right)$

Tout $=25+2.9 /(0.23 \times 4.2)=28^{\circ} \mathrm{C}$

For the sizing of cooling coil, we will use the formula mentioned below for calculating heat for forced convection which will give us the surface area of the coil that should be in contact with the air for the required cooling load of the coil.

$$
Q=h \times A_{s} \times\left(T_{s}-T_{\infty}\right)
$$

Where

$\mathrm{Q}=$ Cooling load or heat generated

$\mathrm{h}=$ Overall heat transfer coefficient between air and water when copper acts as a medium

$\mathrm{A}_{\mathrm{s}}=$ Surface area at which convective heat transfer occurs

$\mathrm{T}_{\mathrm{s}}=$ Surface temperature of the $\mathrm{A}_{\mathrm{s}}$

$\mathrm{T}_{\infty}=$ Temperature of water

$$
\begin{aligned}
& 2900=13.1 \times A_{s} \times(45-25) \\
& A_{s}=2900 / 262=11.06 \mathrm{~m}^{2}=119.04 \mathrm{ft}^{2}
\end{aligned}
$$

If we are taking one cooling coil of an effective face area of $12 \mathrm{ft}^{2}$ then the cooling unit requires 9.92 or approx 10 coils of the same dimensions stacked together to provide an effective surface area of $119.04 \mathrm{ft}^{2}$.

\section{CONCLUSION}

From the given results we concluded that for a cooling load of a room this system was able to maintain an optimal room temperature of $25^{\circ} \mathrm{C}$ with the use of water as a refrigerant. But there is also a significant increase in the use of copper for constructing cooling coils that makes the construction of this system expensive. Although this system is expensive but significantly uses less energy and is more durable than the conventional air cooler. In the future, additives like nanoparticles in water can further increase the efficiency of this system, and also this system can be used in industries where air conditioners and air coolers are not viable for installation.

\section{ACKNOWLEDGEMENT}

We are sincerely thankful to Manav Rachna University, Faridabad for providing us the opportunity to write a research paper on the topic "Designing Geothermal Heating and Cooling System".

\section{REFERENCES}

[1] M. Kumar, S. Kumbare, To Study Earth Tube Heat Exchanger Cooling of Air in Different Month of Bhopal MP, International Journal of Innovative Trends in Engineering (IJITE). 10 (2015) 2729.

[2] G.G. Momin, Experimental Investigation Of Geothermal Air Conditioning, American Journal of Engineering Research (AJER). 2 (n.d.) $157-170$

\section{AUTHOR'S PROFILE}

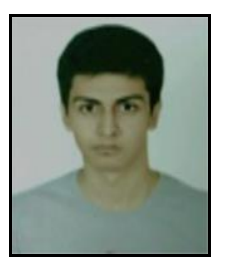

Prateek Mahapatra: B.tech Mechanical Engineering, Department of Mechanical Engineering, Manav Rachna University (MRU), Faridabad. Research areas are Thermal Engineering, Automotive Designs, Internal Combustion Engines and Design Analysis. Published 1 article in Indian Journal of Science and Technology.

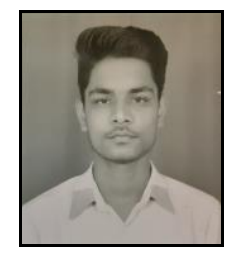

Shivam Singh: B.tech Mechanical Engineering, Department of Mechanical Engineering, Manav Rachna University (MRU), Faridabad. Research areas are Thermal Engineering, Automotive Designs, Internal Combustion Engines and Design Analysis. Published 1 article in Indian Journal of Science and Technology. 